\title{
Introduction to the History of Headache Section
}

This issue of The Journal of

Headache and Pain will feature a new section dedicated to the history of headache. This section will further contribute to the overall objectives of the Journal by dealing with topics which are of particular significance to our profession.

The importance of including history among papers involving basic or clinical research should be closely examined. One reason, and a good one at that, is pleasure: indeed, many of us enjoy, on a cultural basis, the reappraisal of forgotten therapies or of ignored medical practices, along with their historical, social, and artistic background.

But there are other reasons, one of which a physician should immediately perceive, which strongly motivate a historical approach to everyday practical problems. As with our patients we proceed from the history of disease (anamnesis), to understanding its present status (diagnosis), to be able to anticipate its evolution (prognosis); similarly, the study of our past experiences is important for understanding the present and allows us to face future developments.

If history is understood as a succession of events determined by specific causes with specific consequences that vary according to social, economic, and political conditions, a historical analysis is essential for a dynamic interpretation of scientific theories in a social-cultural context of reference. A historical approach to headaches helps highlight the logical connections that have led to a discovery, to a new theory, to conceiving an instrument, or a treatment, and today can still give useful indications and suggestions in daily practice. The study of the contributions of those who, before us, faced similar problems, helps us understand how scientific knowledge has evolved along a difficult and sometimes contradictory course. Our work methodology, which to contemporary eyes seems obvious, is instead the difficult result of experiences, which only the consciousness of one's past can help understand.

"The study of the history of scientific thought is the weapon that frees us progressively from the idola (prejudices) of the intellect": this statement by the renowned historian of medicine, Loris Premuda, with its clear reference to the philosopher Francis Bacon (1561-1626), emphasizes the critical role of history. Thus, the interest for the evolution of one's discipline should rightly be considered an integral part of the interest for the discipline itself.

Medical practice is made more and more difficult by the exponential progress of scientific knowledge, that over time has inevitably fragmented into various specializations and sub- 
specializations. On the one hand, this evolution guarantees continued advancement, with a better understanding of the pathogenesis of headache and therefore in therapy improvement, while on the other hand, there is a risk that it could, in an agitated rush, conduct the physician towards an uncritical acquisition of notions with the possibility of losing the overall patient perspective.

The historical approach, not limited to a sterile accumulation of information acquired uncritically, but founded on a continuous dialogue with the original sources, emphasises the awareness of existing relationships between physician-patient-disease-society and gives the physician useful ethical professional teachings. What emerges is a holistic view of the suffering individual, extremely important for the clinician: the patients, who turn to us with specific headache problems, are individuals who should be considered in their entirety, not only in a biological sense, but also in their psycho- social aspects, and it is at this level that the medical relationship should be set in order to be efficacious.

The above considerations, that is, the possibility through a historical indepth study to acquire, critically, the development of scientific theories; to perceive the bonds between physicianpatient-disease-society; to appreciate the holistic view of the patient and the cultural contents that enrich the medical relationship; to understand the broader view of the field of headaches integrated within an overall picture of the progress of medical knowledge; are only a few of the reasons for launching this Historical Section.

Contributions, such as full papers, short notices or ample debates on pertinent issues will be welcomed.

Section Editor: Giorgio Zanchin Department of Neurosciences Section of History of Medicine Headache Center, University of Padua Via Falloppia 50, I-35121 Padua, Italy e-mail: giorgio.zanchin@unipd.it 